\title{
Budesonide prevents but does not reverse sustained airway hyperresponsiveness
} in mice

\author{
D.S. Southam*, R. Ellis*, J. Wattie*, S. Young* and M.D. Inman*
}

ABSTRACT: Despite the effectiveness of corticosteroids at resolving airway inflammation, they are only moderately effective at attenuating airway hyperresponsiveness (AHR). The extent to which corticosteroids are able to reverse or inhibit the development of sustained AHR is not known. The present study aimed to determine whether budesonide can resolve and or prevent the development of sustained AHR in mice.

Mice were chronically exposed to allergen and treated with budesonide either: 1) briefly during the final weeks of exposure to allergen; 2) prolonged concurrently throughout exposure to allergen; or 3) delayed following final exposure to allergen. AHR was assessed $24 \mathrm{~h}$ (brief treatment) or 4 weeks (prolonged concurrent and delayed treatments) following final exposure to allergen.

Brief budesonide intervention significantly attenuated the inflammation-associated AHR assessed immediately following final exposure to allergen. Similarly, prolonged concurrent budesonide treatment prevented the development of sustained AHR. Delayed budesonide intervention, however, did not resolve sustained AHR.

In conclusion, the early introduction and, importantly, the persistence of corticosteroid treatment prevented the development of sustained airway hyperresponsiveness; however, the inability of corticosteroids to reverse established airway dysfunction indicates a limitation in their use for the complete, long-term management of airway hyperresponsiveness.

KEYWORDS: Airway hyperresponsiveness, asthma, bronchial hyperreactivity, corticosteroid treatment, pathophysiology, remodelling

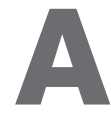
sthma is a heterogenous disease, defined by reversible airway obstruction, and associated with chronic airway inflammation, airway remodelling and airway hyperresponsiveness (AHR). AHR refers to the tendency of the airways to exhibit excessive narrowing in response to various stimuli. AHR is present in nearly all individuals with asthma and often relates to disease severity [1]. The mechanisms underlying AHR appear complex and multifactorial [2]. Although these mechanisms are incompletely understood, airway inflammation and structural remodelling appear to be fundamentally involved [2,3]. A characteristic feature of asthmatic inflammation is the presence of eosinophils. Indeed, the accumulation of eosinophils and their mediators in the airway and periphery correlate significantly with asthma severity, lung function and AHR [4-6].
Airway remodelling, including subepithelial fibrosis, and hyperplasia/hypertrophy of smooth muscle cells may, at least in part, be responsible for AHR [3, 7]. Airway biopsies from asthmatics suggest that both the degree of smooth muscle thickness and the extent of subepithelial fibrosis relate to disease severity [8] and magnitude of AHR [7, 9].

Inhaled corticosteroids (ICS) are the most effective intervention currently available for the management of asthma. They appear to reduce the risk of asthma exacerbations [10], irreversible airway changes [11] and asthma-associated fatalities [12]. Furthermore, evidence suggests that the earlier ICS are introduced, the greater the degree of improvement in lung function [13, 14]. Although early prolonged ICS intervention significantly reduces the asthma-like symptoms and number of exacerbations in children receiving

\section{AFFILIATIONS}

*Firestone Institute for Respiratory Health, Dept of Medicine, McMaster University, Hamilton, ON, Canada. \#AstraZeneca, Research and Development, Charnwood, Loughborough, UK.

CORRESPONDENCE

M.D. Inman

Firestone Institute for Respiratory Health

St. Joseph's Healthcare

50 Charlton Avenue East Hamilton

ON

L8N 4A6

Canada

Fax: 19055406510

E-mail: inmanma@mcmaster.ca

Received:

September 232007

Accepted after revision:

April 302008

SUPPORT STATEMENT

This work was supported by an operating grant from the Canadian Institutes of Health Research (CIHR; Ottawa, ON, Canada). D.S. Southam is an Ontario Graduate Scholar, CIHR Canada Graduate Scholar Doctoral Award recipient and recipient of a National Sciences and Engineering Research Council of Canada (NSERC) Postgraduate Scholar Doctoral Award.

\section{STATEMENT OF INTEREST}

A statement of interest for

S. Young, and for the study itself can be found at www.erj.ersjournals.com/ misc/statements.shtml 
treatment, following the withdrawal of ICS it appears that this early treatment dose not produce long-term benefits [15]. The effectiveness of ICS is generally attributed to their wide spectrum anti-inflammatory properties, which reduce the number of inflammatory cells, especially eosinophils. Whether ICS are effective at reversing indices of airway remodelling in asthma is less clear. While studies have found significant treatment effects on specific indices, including smooth muscle actin in small airways only [16], tenascin [17], endothelin [18] and collagen subtype III [19], these effects appear small and other studies have observed no effects on these or other markers of airway remodelling [16, 20]. Conflicting evidence from experimental models, however, suggests that ICS intervention may attenuate indices of remodelling, including extracellular matrix deposition [21-23] and smooth muscle thickness [22, 23]. The majority of these studies, however, failed to address the effect of ICS intervention on established indices of remodelling. Despite the clear anti-inflammatory and possible anti-remodelling effect of ICS intervention, they are ineffective at completely reversing airway dysfunction observed in human asthma. Indeed, ICS appear to contribute to only a one to two doubling dose improvement in provocative concentration of bronchoconstrictor required to produce a $20 \%$ fall in forced expiratory volume in one second [24-26]. This relatively small attenuation of airway dysfunction is hypothesised to be primarily attributed to a reduction in inflammatory indices. It seems likely that the persistent airway dysfunction is attributable, at least in part, to airway remodelling. While it is clear that ICS intervention is able to attenuate inflammatory-associated AHR in animals [21, 27, 28] and humans [29-31], it is unclear whether ICS intervention is able to prevent or reverse persistent, or sustained, AHR, which characteristically dominates airway dysfunction in human asthma.

A model of airway dysfunction in mice following chronic exposure to allergen has previously been described [32]. In addition to reflecting transient responses to inhaled allergens [32-34], the current model uniquely exhibits airway dysfunction associated with remodelling that persists for $\geqslant 8$ weeks following final allergen exposure, well beyond the resolution of acute inflammatory events. This model is ideally suited to allow the effect of ICS intervention on sustained AHR to be explored.

The purpose of the current study was to: 1) confirm that brief ICS intervention is able to resolve inflammatory-associated AHR; 2) determine whether early prolonged ICS intervention, concurrent with exposure to allergen, is able to prevent the development of sustained AHR; and 3) determine whether delayed ICS intervention following the development of AHR, during allergen avoidance, is able to reverse sustained AHR. It was hypothesised that early prolonged ICS intervention throughout chronic exposure to allergen would prevent the development of sustained AHR, while delayed ICS treatment following chronic exposure to allergen would be ineffective at attenuating sustained AHR.

\section{MATERIALS AND METHODS}

A more detailed description of some of the methods is provided in the online supplementary data.

\section{Animals}

Female BALB/c mice, aged 8-10 weeks, were purchased from Harlan Sprague Dawley Inc. (Indianapolis, IN, USA). Mice were housed using BioBubble technology (BioBubble, Fort Collins, CO, USA) in environmentally controlled specific pathogen-free conditions for the duration of the study. All procedures were reviewed and approved by the Animal Research Ethics Board at McMaster University (Hamilton, ON, Canada).

\section{Allergen exposure}

\section{Chronic protocol}

Mice ( $n=8-10$ per group) were sensitised with intraperitoneal ovalbumin (OVA; $80 \mu \mathrm{g}$ in $200 \mu \mathrm{L}$ saline), precipitated with aluminum potassium sulphate and subsequently challenged intranasally with OVA (100 $\mu \mathrm{g}$ in $25 \mu \mathrm{L}$ saline), as described previously [32, 35]. Mice were studied $24 \mathrm{~h}$ and 4 weeks following chronic exposure to allergen. Control mice were subjected to the same sensitisation protocol but received saline challenges. Control mice were similarly studied $24 \mathrm{~h}$ and 4 weeks following chronic exposure to saline.

\section{Corticosteroid intervention}

Mice ( $n=8-10$ per group) were intraperitoneally injected with $200 \mu \mathrm{L}$ of budesonide $\left(3 \mathrm{mg} \cdot \mathrm{kg}^{-1}\right)$ once daily $\sim 30 \mathrm{~min}$ prior to allergen challenge (a therapeutic dose that was established as the lowest dose capable of preventing increases in airway responsiveness and bronchoalveolar lavage (BAL) eosinophils in a brief allergen exposure protocol; for more details see the online supplementary data). Intervention consisted of: 1) brief daily treatment commencing on day 76 for the remaining 2-week duration of allergen exposure protocol; 2) prolonged concurrent treatment every other day beginning on day 19 for the duration of allergen exposure and the 4-week duration following the cessation of allergen exposure protocol; and 3) delayed treatment every other day beginning on day 91 for the 4-week duration following the cessation of the allergen exposure protocol (fig. 1). Budesonide was suspended in a vehicle of $1 \%$ carboxymethylcellulose solution following $10 \mathrm{~min}$ of sonication according to the recommendations of AstraZeneca (Charnwood, UK). Control mice were subjected to the same treatment protocol but only received vehicle.

\section{Airway responsiveness}

Airway responsiveness was measured based on the response of total respiratory system resistance (Rrs) to saline and increasing intravenous doses $\left(10,33,100\right.$ and $\left.330 \mu \mathrm{g} \cdot \mathrm{kg}^{-1}\right)$ of methacholine (MCh), using the flow interrupter technique as described previously [32, 35]. Maximum Rrs was determined as the maximum MCh-induced Rrs. Airway reactivity was calculated by linear regression as the slope of the line for $R \mathrm{rs}$ at 10,33 and $100 \mu \mathrm{g} \cdot \mathrm{kg}^{-1} \mathrm{MCh}$. Overall AHR, represented by area under the curve (AUC), was calculated as the area below the curve of total $R$ rs in response to 0 (saline), 10, 33, 100 and $330 \mu \mathrm{g} \cdot \mathrm{kg}^{-1} \mathrm{MCh}$.

\section{Bronchoalveolar lavage}

BAL was performed by injecting and withdrawing two $250-\mu \mathrm{L}$ aliquots of PBS as described previously [35]. Cytospins were prepared and differential counts performed. 
a)

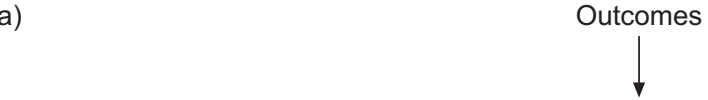

\begin{tabular}{l|llllllll} 
Day 1 & 11 & $19 / 20$ & $33 / 34$ & $47 / 48$ & $61 / 62$ & $75 / 76$ & $89 / 9$ \\
& & & & & & & & \\
OVA IP & IP & & & & & & \\
OVA & IN & IN & IN & IN & IN & IN & IN
\end{tabular}

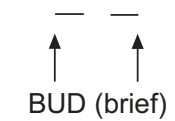

once every day

b)

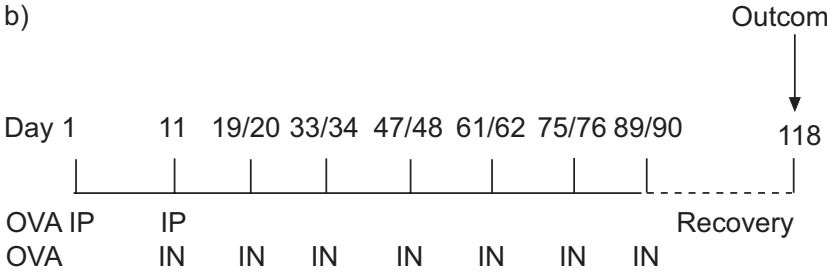

$\begin{array}{lllllllll}\text { OVA } & \text { IN } & \text { IN } & \text { IN } & \text { IN } & \text { IN } & \text { IN } & \text { IN }\end{array}$

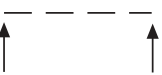

BUD (delayed) once every other day

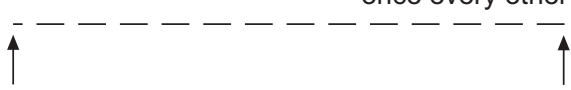

BUD (prolonged)

once every other day

FIGURE 1. Chronic allergen exposure and corticosteroid intervention protocols. Chronic protocol in a) inflammation-associated airway hyperresponsiveness (AHR) and b) sustained AHR. Intraperitoneal (IP) sensitisation with ovalbumin (OVA) was followed by intranasal (IN) challenges with OVA as indicated, while negative control mice received saline. IP budesonide (BUD) intervention (or vehicle for positive and negative control mice) occurred as indicated, either once daily or every other day. Outcomes were made either $24 \mathrm{~h}$ or 4 weeks following final exposure to allergen.

\section{Lung histology and morphometry}

Lungs were dissected, processed and stained as described previously (see online supplementary data) [32, 36]. Tissue sections were stained with picrosirius red or periodic acid-Schiff to quantify collagen deposition or mucin-containing goblet cells, respectively. Additional sections were prepared for immunohistochemistry using a monoclonal antibody against $\alpha$-smooth muscle actin (Clone 1A4; Dako Corporation, Carpinteria, CA, USA) to quantify contractile elements. Morphometric quantification of stained sections was performed using a customised digital image analysis system (Northern Eclipse; Empix Imaging, Mississauga, ON, Canada) as described previously $[32,36]$. Assessment of changes in collagen and smooth muscle actin-positive tissue involved quantifying the percentage of the $20-\mu \mathrm{m}$ band underneath the epithelium that was positive for the stain of interest. For goblet cells, morphometry involved counting the number of mucin positive cells per $\mathrm{mm}$ basement membrane. Morphometric analysis was performed on all mice (eight to 10 per group) and sample images were selected for illustrative purposes.

\section{Statistical analysis}

Reported values are expressed as mean \pm SEM. Data from the saline control were combined, as there was no significant difference between groups in any assessed measurement. Data analysis was performed for planned comparisons using an independent unpaired t-test due to heteroscedasticity of variance. To minimise the probability of type I errors, $\alpha$ was adjusted $<0.05$ using Bonferroni correction, based on the number of comparisons.

\section{RESULTS}

Brief treatment with budesonide during chronic exposure to allergen attenuates inflammation-associated AHR

When assessed immediately following chronic exposure, OVA resulted in AHR comparative to saline control. This AHR was expressed as a significant increase in MCh-induced Rrs $\left(9.3 \pm 1.0\right.$ versus $\left.5.4 \pm 0.3 \mathrm{cmH}_{2} \mathrm{O} \cdot \mathrm{mL}^{-1} \cdot \mathrm{s}^{-1} ; \mathrm{p}<0.001\right)$, airway reactivity (slope of Rrs-MCh dose-response curve; $5.5 \pm 1.1$ versus $2.2 \pm 0.2 ; \mathrm{p}<0.001$ ) and overall AHR (area under RrsMCh dose-response curve; $12.5 \pm 2.2$ versus $5.8 \pm 0.6 ; \mathrm{p}<0.001$ ). This chronic allergen-induced AHR was associated with a significant increase in BAL eosinophils compared with saline control $\left(3.7 \pm 0.5\right.$ versus $0.0 \pm 0.0 \times 10^{4}$ cells; $\left.\mathrm{p}<0.001\right)$. Brief budesonide treatment administered during the final 2 weeks
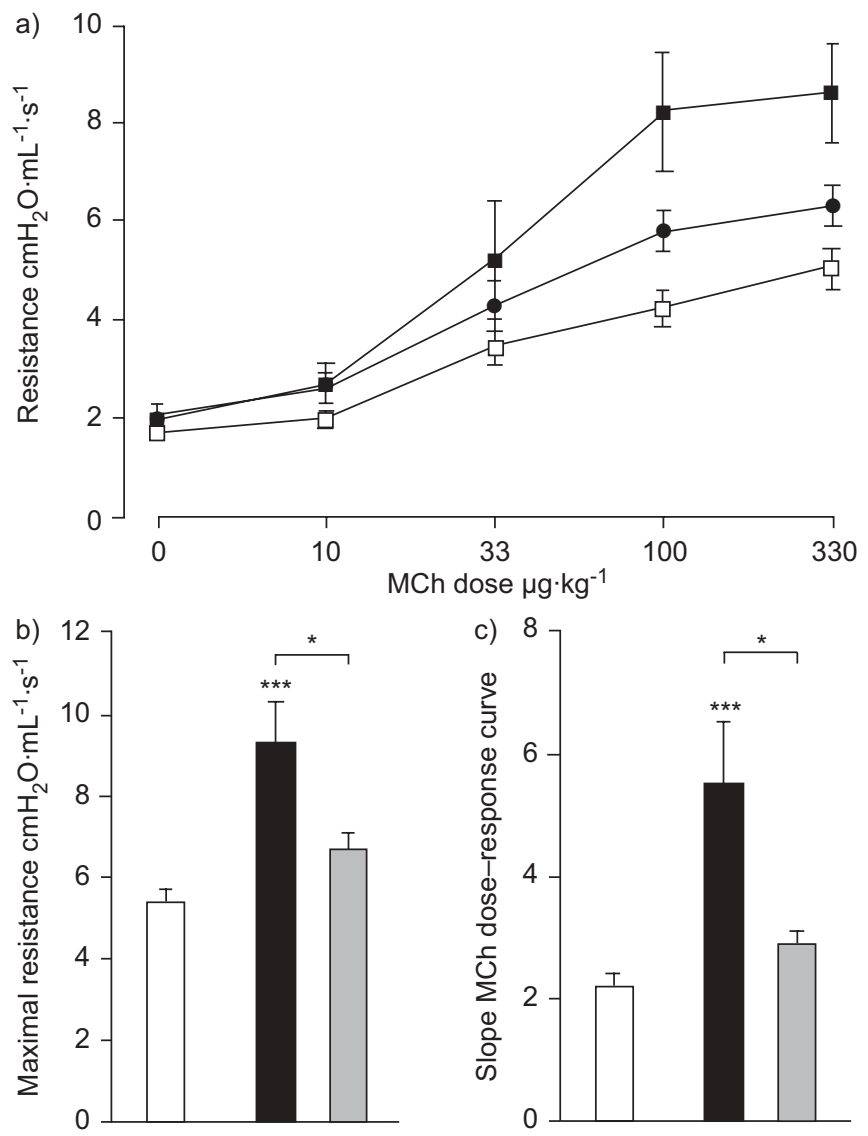

FIGURE 2. a) Airway responses measured $24 \mathrm{~h}$ following chronic exposure to saline (SAL; $\square$ ), ovalbumin (OVA; $\mathbf{\square}$ ), or OVA+brief budesonide (BUD; $\bullet$ ) intervention. Total respiratory system resistance (Rrs)-methacholine (MCh) doseresponse curves were analysed to determine b) maximal airway resistance and c) airway reactivity (slope of Rrs-MCh dose-response curve). Data are presented as mean \pm SEM. $\square$ : SAL; $\mathbf{\square}:$ OVA; $\square:$ OVA+brief BUD. *: $p<0.05$; ${ }^{* * *}: p<0.001$ compared with SAL. 


\begin{tabular}{|c|c|c|c|c|}
\hline \multirow[t]{2}{*}{ TABLE 1} & \multicolumn{4}{|c|}{$\begin{array}{l}\text { Total cells and differentials from bronchoalveolar } \\
\text { lavage performed immediately following chronic } \\
\text { exposure to saline (SAL) or ovalbumin (OVA) }\end{array}$} \\
\hline & & SAL & OVA & OVA+BUD \\
\hline \multicolumn{2}{|l|}{ TCC $\times 10^{2}$} & $567.4 \pm 119.2$ & $937.8 \pm 107.2^{\#}$ & $704.4 \pm 79.7$ \\
\hline \multicolumn{2}{|l|}{ Neutrophils } & $72.5 \pm 50.5$ & $724.4 \pm 233.5^{\#}$ & $750.7 \pm 201.9^{\#}$ \\
\hline \multicolumn{2}{|l|}{ Lymphocytes } & $188.3 \pm 46.6$ & $805.6 \pm 282.0^{\#}$ & $976.1 \pm 246.2^{\#}$ \\
\hline \multicolumn{2}{|c|}{ Eosinophils $\times 10^{2}$} & $1.07 \pm 0.63$ & $340.3 \pm 19.9^{\#}$ & $28.9 \pm 4.9^{\circ}$ \\
\hline \multicolumn{2}{|c|}{ Macrophages $\times 10^{2}$} & $563.3 \pm 118.4$ & $608.8 \pm 77.6$ & $675.3 \pm 97.9$ \\
\hline
\end{tabular}

of chronic OVA exposure significantly attenuated this allergeninduced AHR (fig. 2). The attenuation in AHR comprised a significant decrease in MCh-induced maximal $\operatorname{Rrs}(6.7 \pm 0.4$ versus $\left.9.3 \pm 1.0 \mathrm{cmH}_{2} \mathrm{O} \cdot \mathrm{mL}^{-1} \cdot \mathrm{s}^{-1} ; \mathrm{p}<0.05\right)$, airway reactivity (slope; $2.9 \pm 0.2$ versus $5.5 \pm 1.1 ; \mathrm{p}<0.05$ ), and a strong trend towards a reduction in overall AHR (AUC; $7.8 \pm 0.8$ versus $12.4 \pm 2.2 ; p=0.06)$. While there were significant elevations in BAL total cells, lymphocytes, neutrophils and eosinophils following chronic exposure to allergen (all $p<0.05$ ), a significant treatment effect of budesonide was only observed on eosinophils $(\mathrm{p}<0.001$; table 1$)$.

\section{Prolonged concurrent treatment with budesonide throughout chronic exposure to allergen is able to prevent the development of sustained AHR}

When assessed 4 weeks after chronic exposure, OVA resulted in a sustained AHR compared with control. This AHR was expressed as an increase in maximal $\operatorname{Rrs}(7.7 \pm 0.7$ versus $5.4 \pm 0.3 \mathrm{cmH}_{2} \mathrm{O} \cdot \mathrm{mL}^{-1} \cdot \mathrm{s}^{-1} ; \mathrm{p}<0.001$ ), airway reactivity (slope; $4.2 \pm 0.4$ versus $2.1 \pm 0.2 ; \mathrm{p}<0.001$ ) and overall AHR (AUC; $9.3 \pm 1.1$ versus $5.8 \pm 0.6 ; \mathrm{p}<0.01$; fig. 3 ). The chronic allergeninduced sustained AHR was not associated with an ongoing airway eosinophilia, as these cells resolved to baseline levels by 4 weeks following final allergen exposure $(0.0 \pm 0.0$ versus $3.7 \pm 0.5 \times 10^{4}$ cells; $\left.\mathrm{p}<0.001\right)$. As well as sustained increases in AHR, however, chronic exposure to OVA resulted in a significant increase in collagen staining (as a percentage of the $20-\mu \mathrm{m}$ band underneath the epithelium; $23.7 \pm 1.9$ versus $17.2 \pm 2.2 \%$; $<<0.05$ ), smooth muscle staining (as a percentage of the $20-\mu \mathrm{m}$ band underneath the epithelium $35.0 \pm 1.0$ versus $24.5 \pm 1.9 \% ; \mathrm{p}<0.001$ ) and mucin-containing goblet cells (number per mm basement membrane; $16.2 \pm 3.0$ versus $0.0 \pm 0.0$; $\mathrm{p}<0.001$ ) assessed 4 weeks following final allergen exposure.

When assessed 4 weeks following chronic exposure to allergen, early prolonged concurrent budesonide treatment was able to prevent the development of the allergen-induced sustained AHR (fig. 3). The prevention of AHR following concurrent budesonide intervention was illustrated by the maximal $R$ rs $\left(5.1 \pm 0.3\right.$ versus $\left.7.7 \pm 0.7 \mathrm{cmH}_{2} \mathrm{O} \cdot \mathrm{mL}^{-1} \cdot \mathrm{s}^{-1} ; \mathrm{p}<0.01\right)$, airway reactivity (slope; $1.7 \pm 0.2$ versus $4.2 \pm 0.4 ; \mathrm{p}<0.001$ ) and overall AHR (AUC; $4.7 \pm 0.3$ versus $9.3 \pm 1.1 ; \mathrm{p}<0.01$ ). Prolonged concurrent budesonide treatment significantly prevented indices of airway remodelling, including the allergen-induced increased collagen
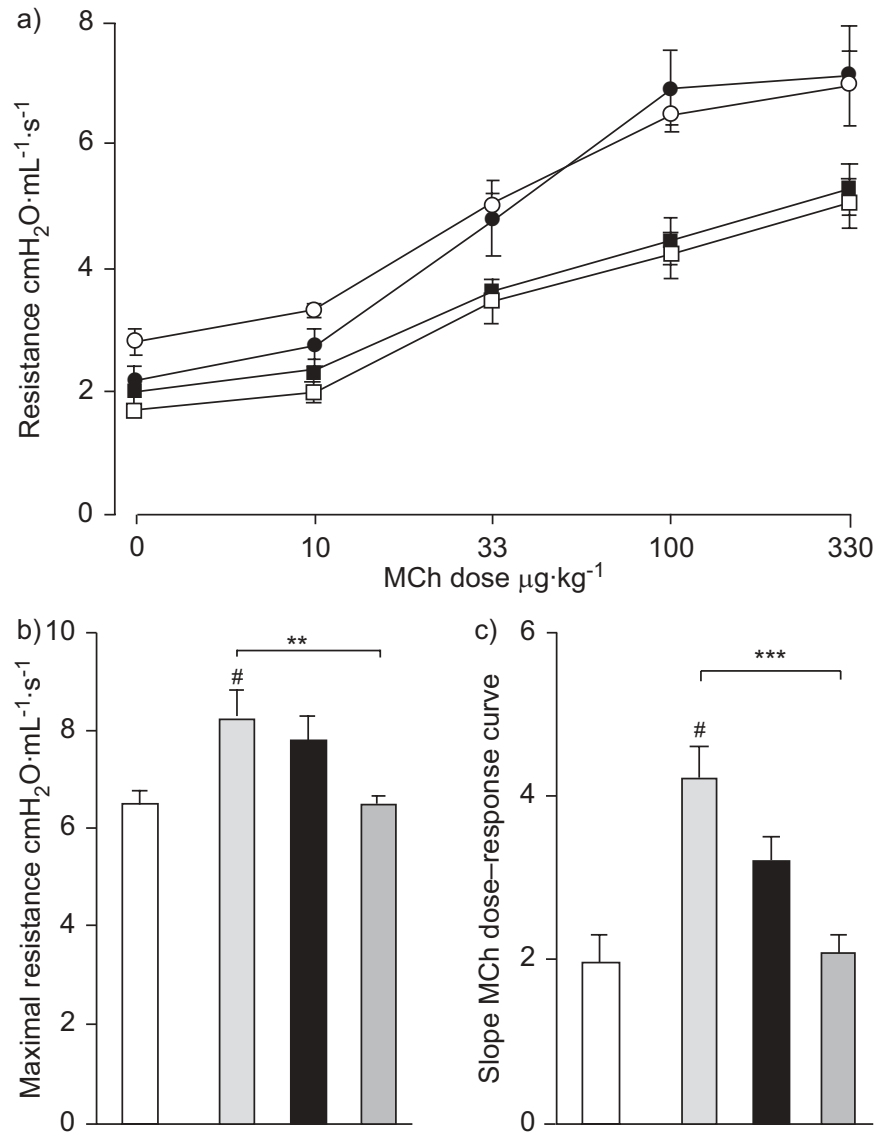

FIGURE 3. Airway responses measured 4 weeks following chronic exposure to saline (SAL; $\square$ ), ovalbumin (OVA; $\bullet$ ), OVA+prolonged budesonide (BUD; $\mathbf{0}$ ) or OVA+delayed BUD $(\bigcirc)$. Total respiratory system resistance (Rrs)-methacholine (MCh) dose-response curves were analysed to determine b) maximal airway resistance and c) airway reactivity (slope of Rrs-MCh dose-response curve). $\square \mathrm{SAL}$

口: OVA; $\mathbf{\square}$ : OVA+delayed BUD; 1 : OVAtprolonged BUD. Data are presented as mean \pm SEM. ${ }^{* *}: \mathrm{p}<0.01 ;{ }^{* * *}: \mathrm{p}<0.001{ }^{*}: \mathrm{p}<0.001$ compared with SAL.

deposition $(15.1 \pm 1.7$ versus $23.7 \pm 1.9 \% ; \mathrm{p}<0.01)$ and mucincontaining goblet cells $(0.7 \pm 0.2$ versus $16.2 \pm 3.0 ; p<0.001)$, with a trend towards preventing the allergen-induced increase in smooth muscle mass $(30.8 \pm 2.2$ versus $35.0 \pm 1.0 \%$; $\mathrm{p}=0.09)$. Morphometric analyses were performed based on images from all study mice (eight to 10 per group) and representative images produced (figs 4 and 5).

\section{Delayed treatment with budesonide following chronic exposure to allergen is unable to reverse sustained $\mathbf{A H R}$}

Delayed budesonide treatment administered during the 4 weeks following chronic exposure to allergen was unable to reverse the allergen-induced sustained AHR (fig. 3). The persistence of $\mathrm{AHR}$, despite delayed budesonide intervention, was illustrated by the maximal $\operatorname{Rrs}\left(7.1 \pm 0.6 \mathrm{cmH}{ }_{2} \mathrm{O} \cdot \mathrm{mL}^{-1} \cdot \mathrm{s}^{-1}\right)$, airway reactivity (slope; $3.2 \pm 0.3$ ), and overall AHR (AUC; $7.6 \pm 0.4$ ). Despite the lack of effect on sustained AHR, delayed budesonide significantly reversed some indices of airway remodelling, including the allergen-induced increase in smooth muscle mass $(24.4 \pm 2.2 \%$ versus $35.0 \pm 1.0 \%$; $<0.001)$ and mucin containing goblet cells $(0.4 \pm 0.2$ versus $16.2 \pm 3.0$; 

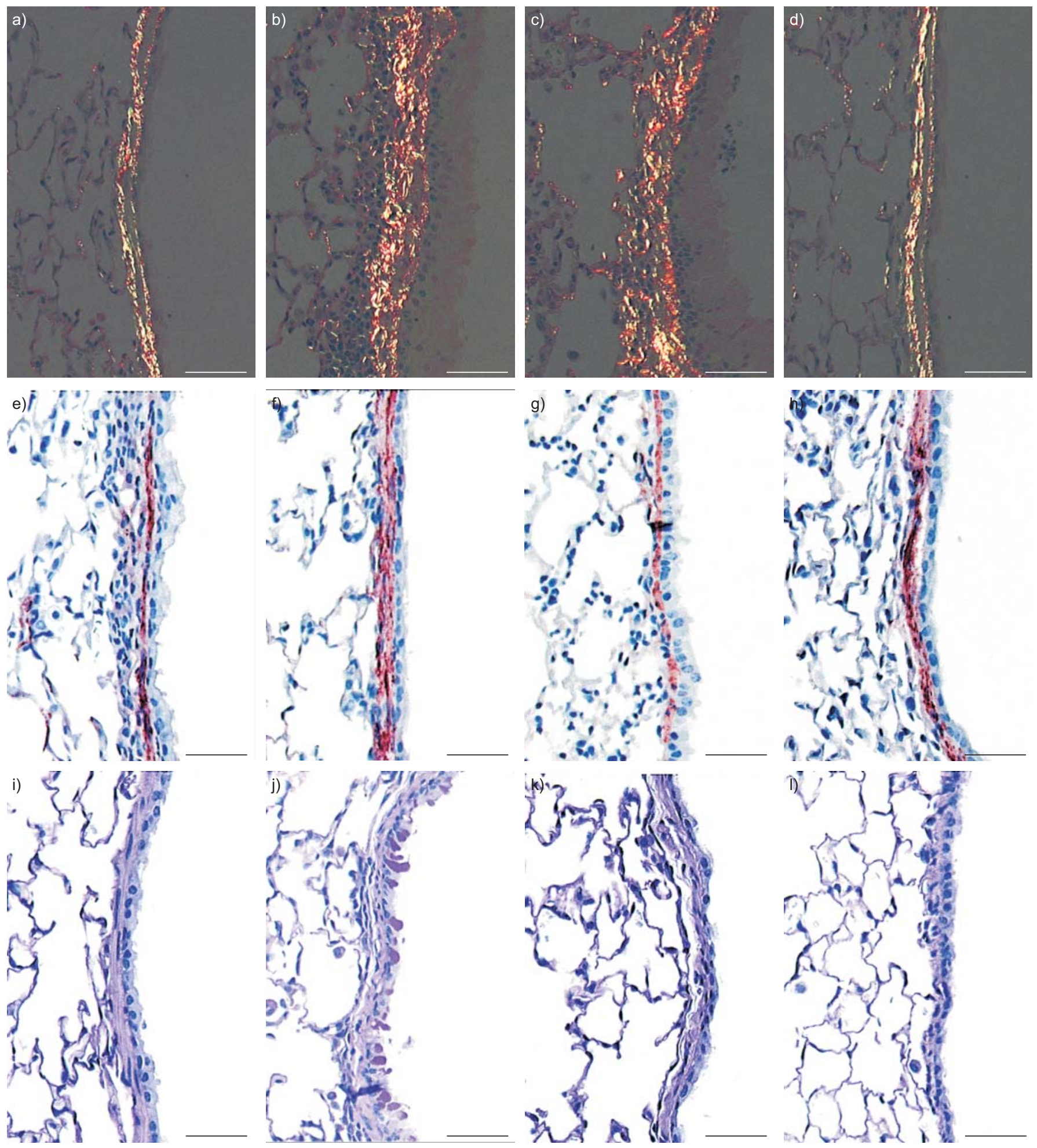

FIGURE 4. Representative morphometric images of a-d) collagen deposition (picrosirius red; viewed using polarised light microscopy), e-h) smooth muscle area $(\alpha$-smooth muscle actin), or i-I) mucin-containing goblet cells in the airways of mice measured 4 weeks after chronic exposure to saline (SAL; a, e, i), ovalbumin (OVA; b, $f, j)$, OVA+delayed budesonide (BUD; c, g, k), or OVA+prolonged BUD (d, h, I). Scale bars $=50 \mu \mathrm{m}$.

$\mathrm{p}<0.001$; figs 4 and 5). Delayed budesonide treatment, however, was unable to reverse the allergen-induced increase in collagen deposition ( $23.1 \pm 1.6$ versus $23.7 \pm 1.9 \%$; figs 4 and 5 ).

\section{DISCUSSION}

The present study has shown that early, prolonged continuous ICS intervention can prevent the development of 

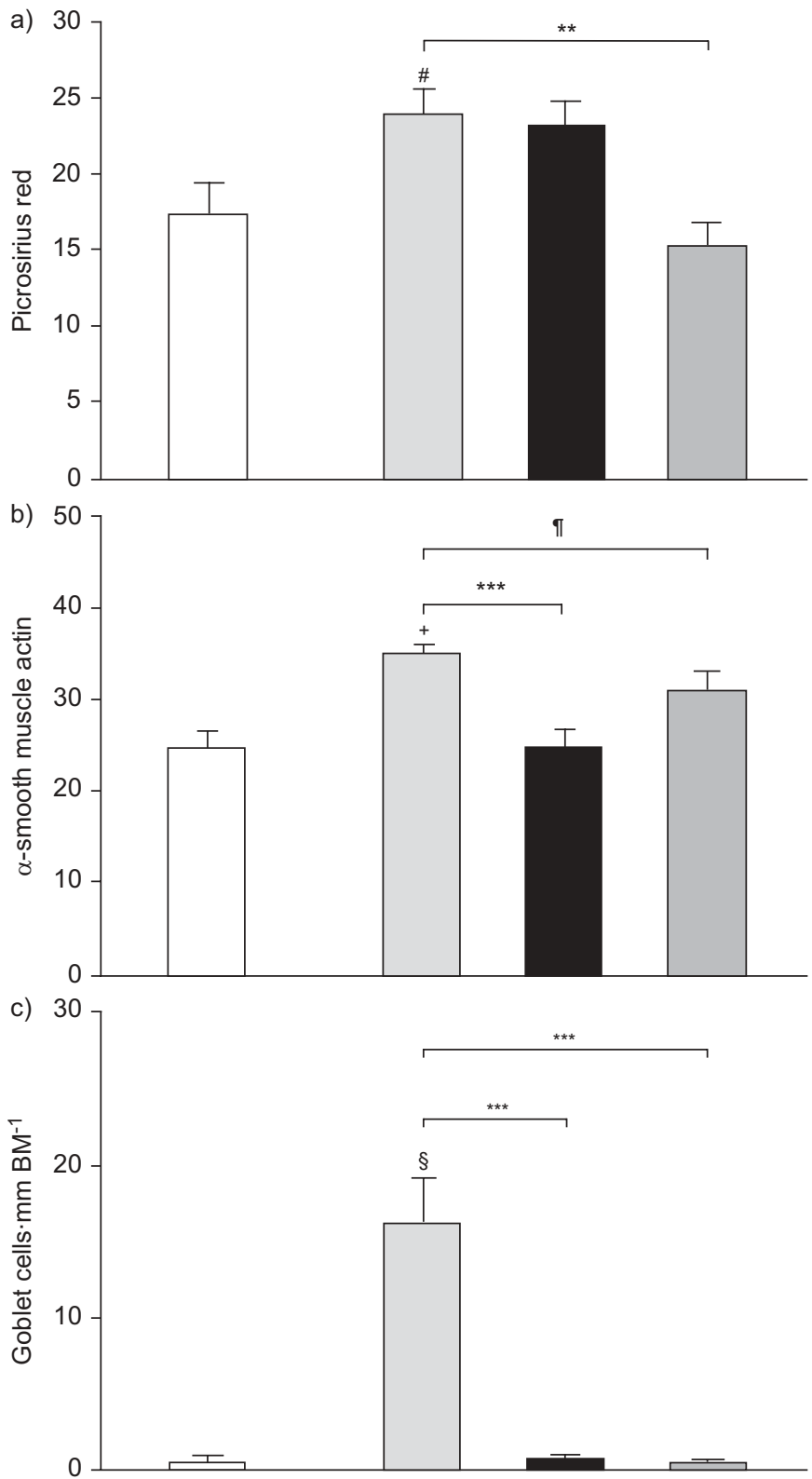

FIGURE 5. Morphometric quantification of a) picrosirius red, b) $\alpha$-smooth muscle actin or c) mucin-containing goblet cells in the airways of mice measured 4 weeks following chronic exposure to saline (SAL; $\square$ ), ovalbumin (OVA; $\square$ ), OVA+prolonged budesonide (BUD; $\square$ ) or OVA+delayed BUD ( $\square$ ). Data are expressed as the percentage of positively stained tissue in the region of interest (see Materials and Methods section for further details) and presented as mean \pm SEM. BM: basement membrane. ${ }^{* *}: p<0.01$; ${ }^{* * *}: p<0.001$; ${ }^{*}: p<0.05$ compared with SAL; ${ }^{\bullet}: p=0.09 ;{ }^{+}: p<0.001$ compared with SAL; ${ }^{\text {s: }} p<0.0001$ compared with SAL.

allergen-induced sustained AHR, while delayed ICS intervention is unable to reverse allergen-induced sustained AHR. Brief treatment with budesonide during the final 2 weeks of chronic exposure to allergen is able to reverse airway eosinophilia and inflammation-associated AHR when assessed $24 \mathrm{~h}$ after final exposure to allergen. Early prolonged budesonide treatment administered continuously during exposure to allergen, and the subsequent period of allergen avoidance, is able to prevent

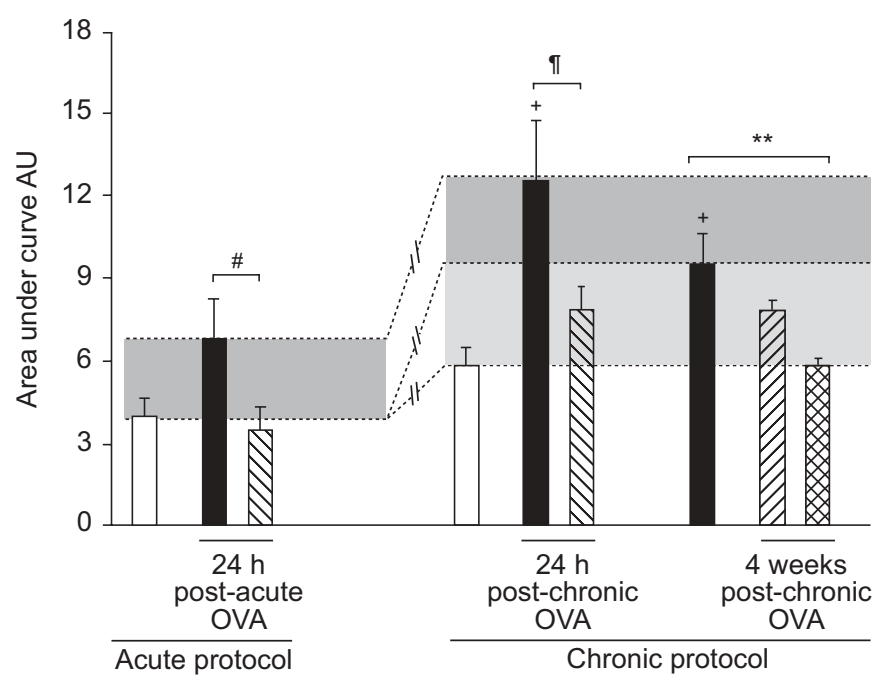

FIGURE 6. Illustration of the hypothesised constituents of airway hyperresponsiveness (AHR). Transient AHR ( $\square$ ), associated primarily with airway inflammation, is present following exposure to allergen and resolves with the resolution of airway inflammation. Sustained AHR ( $\square$ ), associated at least in part with persistent airway remodelling, is present following chronic exposure to allergen and persists following the resolution of airway inflammation. $\square$ : saline; $\mathbf{\square}$ : ovalbumin (OVA); $\mathbb{Z}$ : OVA+brief

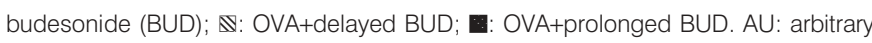
units. ${ }^{* *}: p<0.01 ;{ }^{*}: p=0.03 ;{ }^{\bullet}: p=0.06 ;^{+}: p<0.01$ compared with SAL.

the development of sustained AHR. Conversely, delayed treatment with budesonide during the 4 weeks following chronic exposure to allergen is unable to completely reverse sustained AHR. These findings suggest that early, prolonged concurrent, but not delayed, ICS intervention may be beneficial in the prevention and management of sustained AHR.

It has been confirmed that brief treatment with budesonide is able to reverse airway eosinophilia and AHR assessed immediately following chronic exposure to allergen. This finding is consistent with previous reports in which ICS treatment reduced AHR when assessments were made immediately following exposure to allergen in both animals [21,37] and humans [29-31]. Furthermore, the present authors reported that inhibition of immune-mediated events attenuates AHR [32-34]. These findings support the hypothesis that airway inflammation contributes to AHR. However, given the presence of airway inflammation immediately following exposure to allergen, treatment efficacy on AHR may simply reflect acute anti-inflammatory properties of the intervention, while not addressing the sustained AHR that persists beyond the resolution of airway inflammation. It has previously been reported that the persistence of AHR is not dependent on ongoing airway inflammation [2,32], although it is recognised that early immune-mediated events are likely to be responsible for its development.

In an attempt to determine the effect of ICS intervention on the development of sustained AHR, mice were treated with budesonide concurrently throughout chronic exposure to allergen. This treatment strategy allowed the present authors to prevent the development of allergen-induced airway inflammation. Comparable studies in human asthma would 
be impractical, as they would require long-term pre-emptive ICS treatment, presumably beginning during infancy, prior to the development of asthma. The current findings indicate that the early introduction of prolonged treatment with budesonide throughout chronic exposure to allergen is able to prevent the development of sustained AHR. Taken together, the current findings suggest that the early introduction of ICS therapy, as advocated by current asthma treatment guidelines for improved asthma management $[38,39]$, and importantly that persistent treatment may prevent the development of sustained airway dysfunction. It is worth mentioning that the mice that were protected from sustained AHR with regular concomitant budesonide had not actually been exposed to OVA for the previous 4 weeks. This was because the primary interest was to determine whether treatment could prevent the development of sustained AHR, which needs to be assessed at this time-point. The present authors cannot say for certain that these mice did not have AHR at an earlier time-point. Given that the inhibiting effect of corticosteroids on transient inflammatory-associated AHR is well established, and confirmed in the present study, it was predicted that no AHR would have been observed at earlier time-points.

To determine the effect of ICS intervention on the resolution of sustained AHR, mice were treated with budesonide during a period of allergen avoidance following chronic exposure to allergen. This treatment strategy allowed intervention with ICS after the development of allergen-induced airway inflammation, indices of remodelling and AHR. Comparable experiments in human asthma would be impractical, requiring the complete ablation of airway inflammation in addition to prolonged therapeutic compliance. The current findings indicate that delayed treatment with budesonide is unable to attenuate sustained AHR.

The present study confirms that a major component of AHR persists despite the complete ablation of airway inflammation. Interestingly, the magnitude of AHR that persists following delayed ICS intervention, assessed at a time following the resolution of allergen-induced airway inflammation, is comparable to that observed following brief ICS intervention, assessed immediately following exposure to allergen (fig. 6). This supports the current authors' hypothesis that AHR observed following chronic exposure to allergen is multifaceted, with steroid-sensitive transient and steroid-insensitive sustained components. Indeed, this hypothesis is supported by GRONKE et al. [40], who reported that AHR in asthmatics with short duration of disease was primarily associated with airway inflammation, while AHR in asthmatics with longer duration disease was primarily associated with impaired lung function attributed to ongoing structural alterations. Thus, although ICS intervention offers many therapeutic benefits to asthmatic individuals, including the reduction of severe exacerbations and improvement of asthma control [10, 15], the current findings suggest that delayed ICS treatment strategies initiated once asthma has developed may have limited effectiveness at reversing sustained airway dysfunction. However, it is possible that administering a greater dose, or more frequent delivery, could have resulted in a greater benefit with delayed intervention. More extensive research is certainly required before a definitive statement on the role of steroids in reversing the effects of chronic allergen can be made.
The sustained AHR that persists despite the resolution of transient AHR by ICS intervention is hypothesised to be due, at least in part, to structural remodelling of the airway. The expression of various indices of remodelling, including increased collagen deposition and smooth muscle area, following chronic exposure to allergen that are associated with sustained AHR have previously been reported [32-34]. The present study observed that the prevention of sustained AHR with early prolonged continuous budesonide treatment was associated with the prevention of some, but not all, allergen-induced indices of remodelling. The nature of the attenuation in indices of remodelling is consistent with the study of MiLLER et al. [41] who reported similar protective effects of concurrent dexamethasone treatment on allergeninduced changes in extracellular matrix, but not on smooth muscle in mice. Conversely, the persistence of sustained AHR following delayed budesonide intervention was observed, despite the resolution of the allergen-induced increases in smooth muscle mass. These findings suggest that an aspect of sustained AHR is associated with the persistence of collagen deposition, but independent of smooth muscle mass. In fact, this is consistent with the present authors' recent findings where the development of sustained AHR followed a timecourse similar to that of increases in airway collagen, but slower than increases in smooth muscle actin staining [42]. The incomplete attenuation of indices of remodelling following delayed ICS intervention is also consistent with $\mathrm{CHO}$ et al. [22] who similarly reported the attenuation of smooth muscle area, but not extracellular matrix deposition, following delayed dexamethasone treatment in mice. Although further work is required to fully understand the impact of airway remodelling on AHR, it appears that additional pharmacological strategies beyond ICS intervention are required for optimal management of sustained AHR.

The observation that dissociation between AHR and allergeninduced changes in smooth muscle is at odds with current views on the role of airway smooth muscle in airway dysfunction in asthma [43, 44]. It is important to point out that in the present study only the area occupied by smooth muscle actin positive cells in a cross section of the airway wall was quantified. As there is an obvious importance of smooth muscle in airway narrowing, the present authors are reluctant to suggest that functional changes following chronic exposure to allergen are independent of smooth muscle change. Clearly, possible phenotypic changes in the smooth muscle need to be addressed. Furthermore, it is entirely possible that the aspect of human asthma responsible for major functional changes in smooth muscle is simply not present in this or other murine models. Thus, while the current study supports early introduction of steroids in the prevention of extracellular matrix changes, the present authors warn against overinterpretation of the negative effect on smooth muscle changes.

In the present study a well described animal model of allergeninduced airway dysfunction was used; however, it is important to recognise the limitations of such model systems. Thus, while the effect of ICS intervention on the development and resolution of sustained AHR has begun to be explored, it remains unclear whether animal models effectively undergo the same pathophysiological changes that occur in human disease. The observed changes in airway dysfunction in all 
animal models are relatively small when compared with the many contrasts seen between asthmatic and nonasthmatic individuals. Despite these limitations, it is proposed that further understanding of important, relevant pathophysiological relationships will stem from animal models and permit the identification of improved therapeutic approaches to disease management.

In summary, the current findings suggest that intervention with corticosteroids is ineffective at resolving established sustained airway hyperresponsiveness, even though they are effective at reducing inflammation-associated airway hyperresponsiveness and sustained airway hyperresponsiveness when administered continuously prior to the development of airway dysfunction. Additionally, these findings support the hypothesis that airway hyperresponsiveness is comprised of both transient steroid-sensitive and sustained steroid-insensitive components, and illustrates the importance of making clear distinctions between transient and sustained airway hyperresponsiveness when exploring the efficacy of novel therapeutics. In conclusion, the present finding that corticosteroid treatment was effective at controlling transient, airway inflammation-associated airway hyperresponsiveness and preventing the development of sustained airway hyperresponsiveness clearly supports their use as first-line therapy in asthma. The failure to reverse the sustained inflammationindependent aspect of airway hyperresponsiveness, however, suggests that optimal disease management may not be achievable using corticosteroids alone.

\section{ACKNOWLEDGEMENTS}

The authors acknowledge and appreciate the comments and suggestions from G. Cox, M. Kolb and M. Stampfli (McMaster University, Hamilton, ON, Canada).

\section{REFERENCES}

1 Cockcroft DW, Killian DN, Mellon JJ, Hargreave FE. Bronchial reactivity to inhaled histamine: a method and clinical survey. Clin Allergy 1977; 7: 235-243.

2 O'Byrne PM, Inman MD. Airway hyperresponsiveness. Chest 2003; 123: Suppl. 3, 411S-416S.

3 Laprise C, Laviolette M, Boutet M, Boulet LP. Asymptomatic airway hyperresponsiveness: relationships with airway inflammation and remodelling. Eur Respir J 1999; 14: 63-73.

4 Gleich GJ. Mechanisms of eosinophil-associated inflammation. J Allergy Clin Immunol 2000; 105: 651-663.

5 Bousquet J, Chanez P, Lacoste JY, et al. Eosinophilic inflammation in asthma. N Engl J Med 1990; 323: 1033-1039.

6 Woodruff PG, Khashayar R, Lazarus SC, et al. Relationship between airway inflammation, hyperresponsiveness, and obstruction in asthma. J Allergy Clin Immunol 2001; 108: 753-758.

7 Jeffery PK, Wardlaw AJ, Nelson FC, Collins JV, Kay AB. Bronchial biopsies in asthma. An ultrastructural, quantitative study and correlation with hyperreactivity. Am Rev Respir Dis 1989; 140: 1745-1753.

8 Pepe C, Foley S, Shannon J, et al. Differences in airway remodeling between subjects with severe and moderate asthma. J Allergy Clin Immunol 2005; 116: 544-549.
9 Boulet LP, Laviolette M, Turcotte H, et al. Bronchial subepithelial fibrosis correlates with airway responsiveness to methacholine. Chest 1997; 112: 45-52.

10 O'Byrne PM, Barnes PJ, Rodriguez-Roisin R, et al. Low dose inhaled budesonide and formoterol in mild persistent asthma: the OPTIMA randomized trial. Am J Respir Crit Care Med 2001; 164: 1392-1397.

11 Hansel TT. How do we measure the effectiveness of inhaled corticosteroids in clinical studies? Respir Med 2004; 98: Suppl. B, S9-S15.

12 Suissa S, Ernst P, Benayoun S, Baltzan M, Cai B. Low-dose inhaled corticosteroids and the prevention of death from asthma. N Engl J Med 2000; 343: 332-336.

13 Agertoft L, Pedersen S. Effects of long-term treatment with an inhaled corticosteroid on growth and pulmonary function in asthmatic children. Respir Med 1994; 88: 373-381.

14 Selroos O, Pietinalho A, Lofroos AB, Riska H. Effect of early vs late intervention with inhaled corticosteroids in asthma. Chest 1995; 108: 1228-1234.

15 Guilbert TW, Morgan WJ, Zeiger RS, et al. Long-term inhaled corticosteroids in preschool children at high risk for asthma. N Engl J Med 2006; 354: 1985-1997.

16 Bergeron C, Hauber HP, Gotfried M, et al. Evidence of remodeling in peripheral airways of patients with mild to moderate asthma: effect of hydrofluoroalkane-flunisolide. J Allergy Clin Immunol 2005; 116: 983-989.

17 Laitinen A, Altraja A, Kampe M, Linden M, Virtanen I, Laitinen LA. Tenascin is increased in airway basement membrane of asthmatics and decreased by an inhaled steroid. Am J Respir Crit Care Med 1997; 156: 951-958.

18 Redington AE, Springall DR, Meng $\mathrm{QH}$, et al. Immunoreactive endothelin in bronchial biopsy specimens: increased expression in asthma and modulation by corticosteroid therapy. J Allergy Clin Immunol 1997; 100: 544-552.

19 Hoshino M, Takahashi M, Takai Y, Sim J. Inhaled corticosteroids decrease subepithelial collagen deposition by modulation of the balance between matrix metalloproteinase- 9 and tissue inhibitor of metalloproteinase- 1 expression in asthma. J Allergy Clin Immunol 1999; 104: 356-363.

20 Bergeron C, Boulet LP. Structural changes in airway diseases: characteristics, mechanisms, consequences, and pharmacologic modulation. Chest 2006; 129: 1068-1087.

21 McMillan SJ, Xanthou G, Lloyd CM. Therapeutic administration of budesonide ameliorates allergen-induced airway remodelling. Clin Exp Allergy 2005; 35: 388-396.

22 Cho JY, Miller M, McElwain K, McElwain S, Broide DH. Combination of corticosteroid therapy and allergen avoidance reverses allergen-induced airway remodeling in mice. J Allergy Clin Immunol 2005; 116: 1116-1122.

23 Vanacker NJ, Palmans E, Pauwels RA, Kips JC. Fluticasone inhibits the progression of allergen-induced structural airway changes. Clin Exp Allergy 2002; 32: 914-920.

24 Woolcock AJ, Yan K, Salome CM. Effect of therapy on bronchial hyperresponsiveness in the long-term management of asthma. Clin Allergy 1988; 18: 165-176.

25 Jeffery PK, Godfrey RW, Adelroth E, Nelson F, Rogers A, Johansson SA. Effects of treatment on airway inflammation and thickening of basement membrane reticular collagen in asthma. A quantitative light and electron microscopic study. Am Rev Respir Dis 1992; 145: 890-899. 
26 Boulet LP, Turcotte H, Laviolette M, et al. Airway hyperresponsiveness, inflammation, and subepithelial collagen deposition in recently diagnosed versus long-standing mild asthma. Influence of inhaled corticosteroids. Am J Respir Crit Care Med 2000; 162: 1308-1313.

27 Kim J, McKinley L, Siddiqui J, Bolgos GL, Remick DG. Prevention and reversal of pulmonary inflammation and airway hyperresponsiveness by dexamethasone treatment in a murine model of asthma induced by house dust. Am J Physiol Lung Cell Mol Physiol 2004; 287: L503-L509.

28 Chu HW, Campbell JA, Rino JG, Harbeck RJ, Martin RJ. Inhaled fluticasone propionate reduces concentration of Mycoplasma pneumoniae, inflammation, and bronchial hyperresponsiveness in lungs of mice. J Infect Dis 2004; 189: 1119-1127.

29 Inman MD, Watson RM, Rerecich T, et al. Dose-dependent effects of inhaled mometasone furoate on airway function and inflammation after allergen inhalation challenge. Am J Respir Crit Care Med 2001; 164: 569-574.

30 Gauvreau GM, Sulakvelidze I, Watson RM, Inman MD, Rerecich TJ, O’Byrne PM. Effects of once daily dosing with inhaled budesonide on airway hyperresponsiveness and airway inflammation following repeated low-dose allergen challenge in atopic asthmatics. Clin Exp Allergy 2000; 30: 1235-1243.

31 Leigh R, Vethanayagam D, Yoshida M, et al. Effects of montelukast and budesonide on airway responses and airway inflammation in asthma. Am J Respir Crit Care Med 2002; 166: 1212-1217.

32 Leigh R, Ellis R, Wattie J, et al. Dysfunction and remodeling of the mouse airway persist after resolution of acute allergen-induced airway inflammation. Am J Respir Cell Mol Biol 2002; 27: 526-535.

33 Leigh R, Ellis R, Wattie JN, et al. Type 2 cytokines in the pathogenesis of sustained airway dysfunction and airway remodeling in mice. Am J Respir Crit Care Med 2004; 169: 860-867.

34 Leigh R, Southam DS, Ellis $\mathrm{R}$, et al. T-cell-mediated inflammation does not contribute to the maintenance of airway dysfunction in mice. J Appl Physiol 2004; 97: 2258-2265.

35 Inman MD, Ellis R, Wattie J, Denburg JA, O'Byrne PM. Allergen-induced increase in airway responsiveness, airway eosinophilia, and bone-marrow eosinophil progenitors in mice. Am J Respir Cell Mol Biol 1999; 21: 473-479.

36 Ellis R, Leigh R, Southam D, O'Byrne PM, Inman MD. Morphometric analysis of mouse airways after chronic allergen challenge. Lab Invest 2003; 83: 1285-1291.

37 Vanacker NJ, Palmans E, Pauwels RA, Kips JC. Doserelated effect of inhaled fluticasone on allergen-induced airway changes in rats. Eur Respir J 2002; 20: 873-879.

38 Lemiere C, Bai T, Balter M, et al. Adult Asthma Consensus Guidelines Update 2003. Can Respir J 2004; 11: Suppl. A, 9A-18A.

39 Pauwels RA, Pedersen S, Busse WW, et al. Early intervention with budesonide in mild persistent asthma: a randomised, double-blind trial. Lancet 2003; 361: 1071-1076.

40 Gronke L, Kanniess F, Holz O, Jorres RA, Magnussen H. The relationship between airway hyper-responsiveness, markers of inflammation and lung function depends on the duration of the asthmatic disease. Clin Exp Allergy 2002; 32: 57-63.

41 Miller M, Cho JY, McElwain K, et al. Corticosteroids prevent myofibroblast accumulation and airway remodeling in mice. Am J Physiol Lung Cell Mol Physiol 2006; 290: L162-L169.

42 Southam DS, Ellis R, Wattie J, Inman MD. Components of airway hyperresponsiveness and their associations with inflammation and remodeling in mice. J Allergy Clin Immunol 2007; 119: 848-854.

43 Boulet LP, Chakir J, Dube J, Laprise C, Boutet M, Laviolette M. Airway inflammation and structural changes in airway hyper-responsiveness and asthma: an overview. Can Respir J 1998; 5: 16-21.

44 Pare PD, McParland BE, Seow CY. Structural basis for exaggerated airway narrowing. Can J Physiol Pharmacol 2007; 85: 653-658. 